\title{
PAPERS
}

\section{Toxic bile acids in gastro-oesophageal reflux disease: influence of gastric acidity}

\author{
D Nehra, P Howell, C P Williams, J K Pye, J Beynon
}

\begin{abstract}
Background-Bile acid toxicity has been shown in the gastric, colonic, and hepatic tissues; the effect on oesophageal mucosa is less well known.

Aims-To determine the spectrum of bile acids refluxing in patients with gastrooesophageal reflux disease and its relation to oesophageal $\mathrm{pH}$ using a new technique of combined oesophageal aspiration and pH monitoring.

Methods-Ten asymptomatic subjects and 30 patients with symptoms of gastrooesophageal reflux disease (minimal mucosal injury, erosive oesophagitis (grade 2 or 3 Savary-Miller), Barrett's oesophagus/stricture; $n=10$ in each group) underwent 15 hour continuous oesophageal aspiration with simultaneous $\mathrm{pH}$ monitoring. Bile acid assay of the oesophageal samples was performed using modified high performance liquid chromatography.

Results-The peak bile acid concentration and DeMeester acid scores were significantly higher in the patients with oesophagitis (median bile acid concentration 124 $\mu \mathrm{mol} / 1$; acid score 20.2) and Barrett's oesophagus/stricture (181 $\mu \mathrm{mol} / 1 ; 43.3)$ than patients with minimal injury (14 $\mu \mathrm{mol} / 1$; 12.5$)$ or controls $(0 \mu \mathrm{mol} / 1 ; 11.1)$. The predominant bile acids detected were cholic, taurocholic, and glycocholic acids but there was a significantly greater proportion of secondary bile acids, deoxycholic and taurodeoxycholic acids, in patients with erosive oesophagitis and Barrett's oesophagus/stricture. Although bile acid reflux episodes occurred at variable pH, a temporal relation existed between reflux of taurine conjugates and oesophageal acid exposure $(r=0.58$, $\mathrm{p}=0.009$ ).

Conclusion-Toxic secondary bile acid fractions have been detected in patients with extensive mucosal damage. Mixed reflux is more harmful than acid reflux alone with possible toxic synergism existing between the taurine conjugates and acid.

(Gut 1999;44:598-602)
\end{abstract}

Keywords: bile acids; reflux oesophagitis; Barrett's oesophagus

Bile acid toxicity has been extensively studied but there is a wide variation in the reporting of relative toxicity of the individual bile acid fractions. Much information is based on the toxic effects of bile acids on gastric mucosa, ${ }^{1-3}$ colonic mucosa, ${ }^{45}$ and hepatocytes, ${ }^{67}$ but little information is available on the toxicity to oesophageal mucosa in reflux disease. Reflux of bile acids in the oesophagus has been estimated indirectly by "alkaline" reflux episodes on $\mathrm{pH}$ monitoring 89 or by measuring bilirubin using the Bilitec 2000 spectrophotometric probe, ${ }^{10-12}$ but these methods are unreliable in quantifying reflux. The concentrations of bile acids and their toxic effects are known to vary with $\mathrm{pH}$ depending on the degree of ionisation. Unconjugated bile acids and glycine conjugates whose $\mathrm{p} K_{\mathrm{a}}$ values are more than 4 and 6 , respectively, precipitate in solutions with $\mathrm{pH}$ less than 4 , whereas taurine conjugates are freely soluble even at pH $2 .{ }^{13}{ }^{14}$ Oesophageal perfusion studies in animal models have shown that unconjugated bile acids cause mucosal damage selectively in alkaline solutions whereas taurine conjugates are toxic in acidic conditions. ${ }^{15} 16$ We have shown, using a new device ${ }^{17}$ for sampling of oesophageal fluid, that there is an association between the degree of oesophageal mucosal injury and concentrations of bile acids refluxing in patients with gastro-oesophageal reflux disease. ${ }^{18}$ In this paper we report the results of bile acid assay of conjugated and unconjugated fractions and investigate the temporal relation between the individual bile acid concentration and oesophageal $\mathrm{pH}$.

\section{Patients and methods}

PATIENTS

Ten asymptomatic volunteers (male:female ratio $4: 1$; median age 28.5 years, range $19-50$ ) and 30 patients (male:female ratio $2: 1$; median age 58.5 years, range $27-79$ ) with symptoms of gastro-oesophageal reflux disease (minimal mucosal injury, $\mathrm{n}=10$; erosive oesophagitis, $n=10$; Barrett's oesophagus/stricture, $n=10$ ) underwent oesophageal aspiration studies with

Abbreviations used in this paper: HPLC, high performance liquid chromatography.
Surgery C2, University

Hospital Wales, Heath Park,

Cardiff CF4 4XW, UK.

Accepted for publication 17 December 1998 


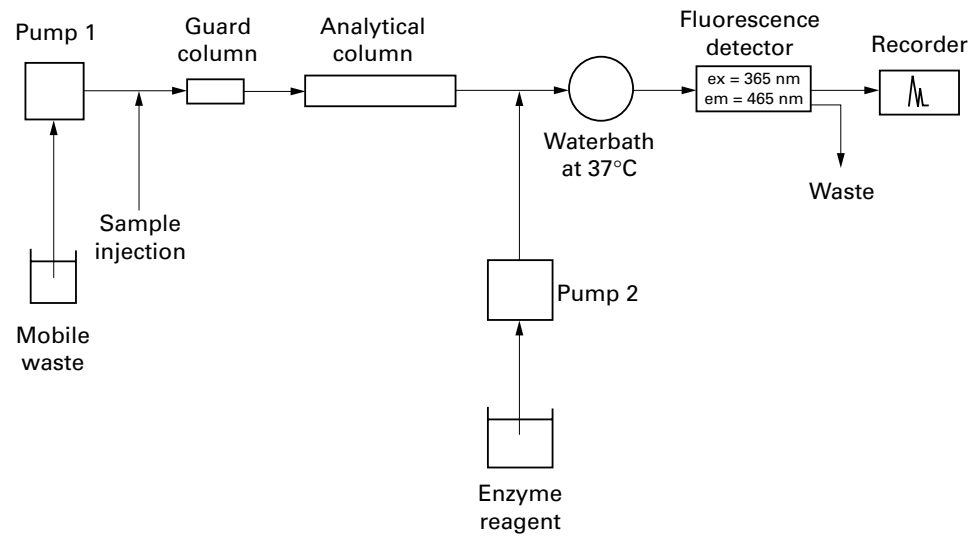

Figure 1. Flow diagram of the modified HPLC method of bile acid assay, combining an enzymatic postcolumn derivation step.

$\mathrm{pH}$ monitoring. The study protocol was approved by the Ethics Committee at the Wrexham Maelor Hospital, Wrexham, UK.

\section{PROCEDURE}

The study was performed as an inpatient procedure over 15 hours between 1800 and 0900. All medication was stopped one week prior to the test. The patients were sitting or reclined during the early period of the study (four hours) and supine at night. The study was commenced four hours after a main meal and included a period of one to two hours to allow the effects of intubation to subside; during the procedure the subjects were restricted to fluids.

A combined $14 \mathrm{~F}$ double channel sump tube (Zinetics Medical, Salt Lake City, Utah, USA) incorporating an antimony $\mathrm{pH}$ detector was passed nasally and the tip positioned to lie $5 \mathrm{~cm}$ above the manometrically located lower oesophageal sphincter. This tube was attached to the suction channel of the purpose built automated suction device. The main component of this device was a 24 volt peristaltic pump (No. 900-0624, Cole-Parmer, USA) connected to a Scorpion K40 microprocessor. A system of fibreoptic liquid detectors and pressure transducers was incorporated in the suction channel to monitor the flow and delivery of the aspirates into a standard biochemical sample receiver. The detailed design and functional aspects of this device have been described previously. ${ }^{17}$ Peripheral control through software programming allowed a different set of aspiration protocols to be used in the oesophageal sampling process. An autoregulated suction pressure (maximum $150 \mathrm{~mm} \mathrm{Hg}$ ) was applied and the oesophageal aspirates were collected as individual samples in autoanalyser cups (capacity $1.6 \mathrm{ml}$ ) resting on a rotating carousel. The onset of each sample retrieval and duration of collection was logged in the memory of the device. The samples were stored at $-20^{\circ} \mathrm{C}$ and later assayed for bile acids using high performance liquid chromatography (HPLC).

A solid state $\mathrm{pH}$ logger (Oakfield Instruments, Oxon, UK) was used to monitor oesophageal $\mathrm{pH}$ simultaneously. The $\mathrm{pH}$ was measured every six seconds and stored in the $\mathrm{pH}$ logger. These data were downloaded to a personal computer as a file and matched with the data of sample retrieval.

MODIFIED HPLC METHOD OF BILE ACID ASSAY Figure 1 presents a flow diagram of the procedure. The HPLC equipment used was a Kontron 420 solvent delivery system (Kontron Instrument, Watford, UK) with an HP Vectra 5 microprocessor controller running the Kontron control software. The HPLC method of bile acid assay was modified using a postcolumn derivation step; the bile acids themselves were separated by the chromatography but the individual bile acids were then reacted with the enzyme 3- $\alpha$ hydroxy steroid dehydrogenase using NAD (nicotamide adenine dinucleotide) as cofactor. The end product of this postcolumn reaction was the fluorescent species $\mathrm{NADH}$ (nicotamide adenine dinucleotide, reduced form) and the bile acids were quantified using a Jasco 821-FP fluorescence spectrophotometric detector (Ciba Corning Diagnostics, Halstead, UK). This step improved the specificity and sensitivity of the technique allowing a clear resolution of 14 bile acid fractions with an elution time of 35 minutes per sample. The analytical column (stationary phase) of the HPLC was a single Spherisorb S5 ODS2 column $(25 \mathrm{~cm} \times 4.6 \mathrm{~mm}$ internal diameter; Waters Corporation, Milford, Massachusetts, USA) with a porous, spherical silica based packing. Oesophageal aspirates contaminated with particulate material were centrifuged at $4000 \mathrm{rpm}(3400 \mathrm{~g})$ for five minutes. The bile acids from the oesophageal samples were extracted using C18 octadectyl endcapped clean up extraction tubes (Technicol, Stockport, UK) using methanol as the solvent. A $20 \mu \mathrm{l}$ sample was injected into a high pressure mobile phase of the HPLC. The mobile phase was prepared by mixing methanol ( $9 \%$ $\mathrm{vol} / \mathrm{vol})$, phosphate buffer ( $90 \% \mathrm{vol} / \mathrm{vol})$, and tetrahydrofuran $(1 \% \mathrm{vol} / \mathrm{vol})$ and $\mathrm{pH}$ adjusted to $\mathrm{pH} 3.5$ with orthophosphoric acid. The mobile phase flow rate was $0.3 \mathrm{ml} / \mathrm{min}$ at 1500 psi and at an ambient temperature of $22-23^{\circ} \mathrm{C}$. The specificity of the HPLC assay was validated for this study by exact overlap of the corresponding peaks of bile acids in oesophageal aspirates and bile acid standards, with consistent analytical recovery and linear response for retention times.

DATA ANALYSIS AND STATISTICS

Bile acid concentrations of the oesophageal samples were matched with the $\mathrm{pH}$ data to obtain combined bile acid and $\mathrm{pH}$ profiles for each patient. The overall differences in the peak bile acid concentrations between groups were compared using the Kruskal-Wallis and the Mann-Whitney $U$ tests. The relation between bile acid and oesophageal $\mathrm{pH}$ was assessed by correlating the concentration of individual bile acids present in the patient's refluxate with the corresponding oesophageal acid exposure (percentage of the total time the $\mathrm{pH}$ was less than 4) using Spearman's correlation coefficients. The patients were further categorised according to their prevailing reflux pattern into acid refluxers (percentage of the 
Table 1 Results of bile acid assay (median peak bile acid concentration and range) and oesophageal pH profile (median and interquartile range)

\begin{tabular}{lllll}
\hline Group & Normal & Minimal & Erosive & $\begin{array}{l}\text { Barrett's } \\
\text { oesophagus/stricture }\end{array}$ \\
\hline $\begin{array}{l}\text { Primary bile acids } \\
\text { Cholic acid }\end{array}$ & $0(0-8)$ & $0(0-99)^{\star}$ & $34(0-150)^{\star}$ & $25(0-126)^{\star}$ \\
$\quad$ Taurocholic acid & $0(0-8)$ & $7(0-67)^{\star}$ & $21(0-198)^{\star}$ & $39(4-131) \dagger$ \\
$\begin{array}{l}\text { Glycocholic acid } \\
\text { Secondary bile acids }\end{array}$ & $0(0-6)$ & $7(0-102)^{\star}$ & $21(0-88)^{\star}$ & $27(0-95)^{\star}$ \\
$\quad$ Deoxycholic acid & $0(0-3)$ & $0(0-7)$ & $2(0-230) \dagger$ & $0(0-282) \dagger$ \\
$\quad$ Taurodeoxycholic acid & $0(0-0)$ & $0(0-0)$ & $0(0-157) \dagger$ & $5.5(0-410) \dagger$ \\
$\quad$ Glycodeoxycholic acid & $0(0-0)$ & $0(0-47)$ & $2.5(0-285)^{\star}$ & $0(0-72)$ \\
$\quad$ Taurolithocholic acid & $0(0-0)$ & $0(0-0)$ & $0(0-0)$ & $6(0-482) \ddagger$ \\
Total bile acid concentration & $0(0-16)$ & $14(0-257)^{\star}$ & $124(6-1020) \dagger$ & $181(30-820) \dagger$ \\
Oesophageal pH & & & & \\
$\quad \%$ time pH<4 & $2.1(0.9-12.1)$ & $2.7(1.3-5.9)$ & $5.1(3.6-12.1)$ & $22.3(10.0-46.0) \ddagger$ \\
DeMeester acid score & $11.1(7.5-25.6)$ & $12.5(8.8-20.4)$ & $20.2(13.7-36.0) \ddagger$ & $43.3(30.6-83.0) \dagger$ \\
\hline
\end{tabular}

${ }^{\star} \mathrm{p}<0.05$ versus normal; $\nmid \mathrm{p}<0.05$ versus normal and minimal; $\neq \mathrm{p}<0.05$ versus normal, minimal, and erosive (Mann-Whitney $\mathrm{U}$ test). $0=$ less than the limit of sensitivity $(0.25 \mu \mathrm{mol} / 1)$.

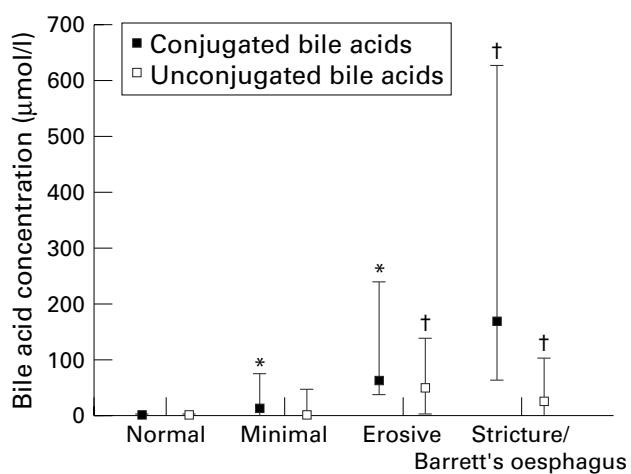

Figure 2 Distribution of conjugated and unconjugated bile acids in each group. Interquartile range and medians are represented. ${ }^{*} p<0.05$ versus normal; $t p<0.05$ versu normal and minimal (Mann-Whitney $U$ test).

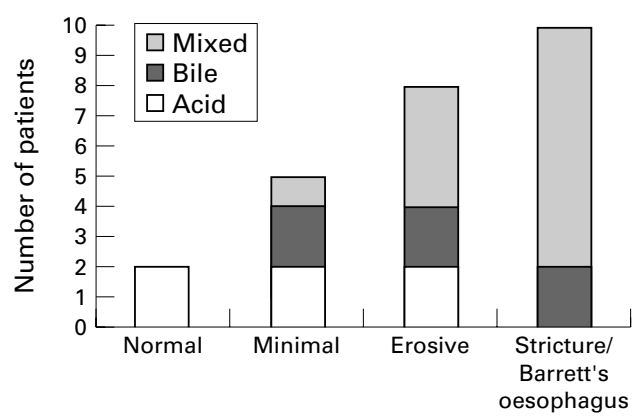

Figure 3 Prevalence of the reflux pattern in each group categorised as acid refluxers, bile acid refluxers, and mixed bile acid and acid refluxers.

total time $\mathrm{pH}<4$ greater than $4.4 \%$ ), bile refluxers (oesophageal bile acid exposure of concentrations greater than $100 \mu \mathrm{mol} / 1)$, and mixed refluxers (acid and bile acid).

\section{Results}

The pattern of reflux episodes observed on the individual patient bile acid and $\mathrm{pH}$ profiles showed that bile acids refluxed at variable $\mathrm{pH}$, although in most instances bile acids refluxed concurrently with acid. Table 1 shows the results of the oesophageal bile acid assay, expressed as the medians (range) of the peak concentrations of individual bile acid fractions in each group. The total bile acid concentrations in the patient groups with erosive oesophagitis (median 124 $\mu \mathrm{mol} / \mathrm{l}$ ) and Barrett's oesophagus/stricture (median $181 \mu \mathrm{mol} / \mathrm{l}$ ) were significantly greater than in the group with minimal injury (median 14 $\mu \mathrm{mol} / \mathrm{l})$. Five patients in the Barrett's oesophagus group had reflux episodes with bile acid concentrations in excess of $200 \mu \mathrm{mol} / 1$. The control group (asymptomatic subjects) had negligible bile acid reflux. Oesophageal acid exposure time was greater with increasing grade of mucosal injury with significantly higher DeMeester acid scores in the oesophagitis and Barrett's oesophagus/stricture groups.

The predominant bile acid fractions detected in the patient groups were the primary bile acids, cholic acid, taurocholic acid, and glycocholic acid. Although these primary bile acids were found in increasingly higher concentrations in patient groups with progressive oesophageal mucosal injury, only taurocholic acid was significantly increased in the Barrett's oesophagus/stricture group compared with the minimal injury group. The dihydroxy and monohydroxy secondary bile acids appeared more frequently in the bile acid profiles of patients with severe oesophagitis.

Taurodeoxycholic acid was found in significantly higher concentrations in the refluxates of patients with erosive oesophagitis and Barrett's oesophagus/stricture while lower but significant concentrations of taurolithocholic acid were detected in the latter group. Figure 2 shows the total concentration of conjugated and unconjugated bile acids in each of the studied groups. There was a significant preponderance of the unconjugated bile acids in the erosive and Barrett's oesophagus groups. Other bile acids detected in low concentrations were taurodeoxycholic, glycochenodeoxycholic, and glycodeoxycholic acids.

Figure 3 shows the pattern of reflux represented by the prevalence of acid reflux, bile acid reflux, and mixed reflux in each group. All of the 10 patients in the Barrett's oesophagus/stricture group were gross refluxers. The prevalence of mixed reflux in eight patients $(80 \%)$ was the highest in this group; it occurred in four patients (40\%) with erosive oesophagitis and only in one patient $(10 \%)$ in the minimal injury group. Overall, six patients $(20 \%)$ had significant bile reflux in the absence of increased oesophageal acid exposure. Although the control subjects denied having reflux symptoms, in two an increased oesophageal acid exposure was recorded. 
Table 2 Results of Spearman's rank correlation analysis between the total/individual bile acid fractions with percentage of the total time $\mathrm{pH}<4$

\begin{tabular}{lll}
\hline Bile acid & $n$ & $p H<4$ \\
\hline Glycine conjugated & 22 & 0.2 \\
Taurine conjugated & 24 & $0.58^{\star}$ \\
Unconjugated & 19 & 0.38 \\
Total & 25 & 0.36 \\
\hline
\end{tabular}

${ }^{\star} \mathrm{p}=0.009$.

Table 2 shows the correlation between individual bile acid concentration and oesophageal acid exposure. There was no correlation between the total bile acid concentration and the oesophageal acid exposure but there was specifically a positive correlation between the concentration of taurine conjugated bile acids in the refluxate and percentage acid exposure $(r=0.58, \mathrm{p}=0.009)$.

\section{Discussion}

Using prolonged oesophageal aspiration studies, followed by HPLC separation of bile acids, we have shown reflux of bile acids in concentrations greater than $200 \mu \mathrm{mol} / 1$ in $50 \%$ of the patients with severe oesophagitis and Barrett's metaplasia. Bile acid concentrations in this range have been found to cause damage to the ultrastructure of the oesophageal epithelium in the presence of acidic $\mathrm{pH} .{ }^{19}$ A significant proportion of the bile acids in patients with extensive mucosal injury was composed of the dehydroxylated taurodeoxycholic acid and the unconjugated cholic and deoxycholic acids. The toxicity of bile acids, attributed to their complex solubility properties based on the individual $\mathrm{p} K_{\mathrm{a}}$ values and micelle formation, have been shown to be inversely proportional to the number of hydroxyl groups on the steroid nucleus. ${ }^{20}$ There has also been considerable interest in the effects of free bile acids (cholic, deoxycholic, and chenodeoxycholic acids), mainly because of the association of excessive bile acid deconjugation in the small intestine. These bile acids inhibit the main active transport systems for glucose, amino acids, and sodium in the jejunum ${ }^{212}$ and cause extensive damage with loss of villi. ${ }^{23}$ Likewise the dihydroxy bile acids have been shown to depress notably a number of metabolic processes in the liver ${ }^{6}$ and the degree of hepatocellular damage is related to bile acid hydrophobicity. ${ }^{7}$ Recent data suggest that toxic bile acids are mitochondrial toxins. ${ }^{24}$

In this study the most common bile acids present in the refluxate were taurocholic, glycocholic, and cholic acids. A few studies have attempted to measure the bile acid fractions using oesophageal aspiration techniques and also found a predominance of the conjugated bile acids, taurocholic and glycocholic acids, in the oesophageal refluxate..$^{25}$ These bile acids were significantly higher in the patients with oesophagitis and Barrett's oesophagus's but only in the postprandial period. The temporal association of bile acid reflux with oesophageal $\mathrm{pH}$ is unclear. Stoker and colleagues ${ }^{27}$ showed that there was a weakly positive correlation between bile salt concentration and increasing $\mathrm{pH}$ in samples of oesophageal fluid aspirated during routine endoscopy. None of the samples, however, had a $\mathrm{pH}$ of more than 6.9 (mean 4.0), suggesting that bile reflux occurred at an acidic or neutral $\mathrm{pH}$. Prolonged oesophageal aspiration studies ${ }^{25}{ }^{28}$ have shown that the episodes of acid reflux were recorded at all time periods during which conjugated bile acids were detected, but Stein et $a l,{ }^{29}$ who performed ambulatory oesophageal aspiration, found a significant correlation between the bile acid concentrations in the aspirates and the percentage of time the $\mathrm{pH}$ was above 7 ; both were highest at night. These studies lack accuracy in their attempt to compare the temporal relation between bile acid reflux and oesophageal $\mathrm{pH}$, mainly because they involve analysis of pooled aspirates. An improved sampling technique in this study has permitted a more precise temporal comparison between the various bile acids in the refluxate and the oesophageal $\mathrm{pH}$. Bile acids refluxed over a wide $\mathrm{pH}$ range although the predominant pattern was that of mixed bile acid and acid reflux as observed in the majority of patients with Barrett's oesophagus/stricture. There was evidence, however, that bile acids can reflux independently without increased acid reflux. These patients presumably had either overwhelming reflux of relatively alkaline duodenal contents or their gastric acid production was suppressed.

A correlation study indicated a temporal relation between taurine conjugated bile acids and the presence of acid. The influence of gastric acidity on bile acid toxicity has not been investigated in humans. Animal model studies on the influence of acid on various components of duodenogastric reflux have shown a damaging potential between pepsin and taurine conjugated bile acids in acidic conditions, ${ }^{1630}$ whereas trypsin and unconjugated bile acids have been found to be damaging in alkaline conditions. ${ }^{31}{ }^{32}$ Armstrong et $a l,^{33}$ studying the relative toxicity of 12 bile acid fractions in a rat gastric mucosa model, showed that at neutral $\mathrm{pH}$ the most gastrotoxic bile acids were the unconjugated forms of the dihydroxy bile acids. They also confirmed that acidification led to precipitation of unconjugated and glycine conjugated bile acids, and was associated with diminished toxicity, while the toxicity of taurine conjugates in general was unaffected at an acidic $\mathrm{pH}$. This may partly explain the reason for the higher concentration of taurine conjugates in patients with increased acid reflux when the glycine conjugates are likely to get precipitated. Nevertheless, the detection of bile acids at higher $\mathrm{pH}$ may explain why overall $15-20 \%$ of patients fail to respond to acid suppression therapy alone. ${ }^{34}$ It can also be speculated that by maintaining a high $\mathrm{pH}$ milieu it is possible that the toxicity of some of these bile acids, particularly the unconjugated fraction, could be potentiated. The $\mathrm{pH}$ range between 4 and 7 may represent the "danger zone" when most bile acids exist in a two phase state, the ionised and unionised phase. The unionised form of bile acids tends to diffuse through the mucosa more efficiently than the ionised form and is regarded as being more 
injurious. ${ }^{35}$ Although bile acids enhance $\mathrm{H}^{+}$ion permeability, there is evidence to suggest that secondary bile acids are able to cause mucosal injury independent of acid, ${ }^{36}$ with increases in amiloride sensitive $\mathrm{Na}^{+}$conductance at the cellular level.

Unconjugated bile acids in the stomach have been found after partial gastrectomy ${ }^{237} 38$ and in the oesophagus after total gastrectomy, ${ }^{39}$ but they have not been shown to reflux in patients with an intact stomach. Other studies have shown that patients on long term omeprazole have diminished acid secretion, causing overgrowth of duodenal and gastric microflora, ${ }^{40}{ }^{41}$ which has been associated with an increase in the concentration of the toxic unconjugated and dehydroxylated acids in the stomach. ${ }^{37}$ Although no direct relation was shown in this study we believe this is a possible explanation for the detection of unconjugated bile acids in patients with oesophageal injury, the majority of whom had in the past received proton pump inhibitors over prolonged periods.

Simultaneous oesophageal bile acid assay and $\mathrm{pH}$ monitoring using a new technique has permitted us to perform an accurate correlation between the two components. The results of the bile acid assay were generally congruent with their known physicochemical properties. Mixed (acid and bile acid) reflux was the dominant pattern of reflux in patients with severe mucosal injury. The results support the theory that $\mathrm{pH}$ of the refluxate modulates the toxic effects of bile acids by influencing their concentrations and that it is possible for oesophageal mucosal damage to occur at $\mathrm{pH}$ greater than 4. A consistent finding of secondary bile acids in patients with Barrett's oesophagus's suggests that these bile acids may contribute to the metaplastic change. A paper based on this work was presented at the British Society
of Gastroenterology, Spring meeting, April 1995 (Spectrum of of Gastroenterology, Spring meeting, April 1995 (Spectrum of
bile acid reflux in gastro-oesophageal reflux disease using a new bile acid reflux in gastro-oesophageal reflux disease using a new
device to sample the distal oesophagus), and published in device to sample the distal oesophagus),
abstract form (Gut 1995;36(suppl 1):A29).

1 Black RB, Hole D, Rhodes J. Bile damage to the gastric mucosal barrier: the influence of $\mathrm{pH}$ and bile acid concenmucosal barrier: the influence of $\mathrm{pH}$

2 Gadacz T, Zuidema G. Bile acid composition in patients with and without symptoms of postoperative reflux gastritis. Am F Surg 1978;135:48-52

3 Gillen P, Keeling P, Byrne PJ, et al. Implication of duodenogastric reflux in the pathogenesis of Barrett's oesophagus. Br F Surg 1988;75:540-3.

4 Turjman N, Nair PP. Nature of tissue bound lithocholic acid and its implication in the role of bile acids in carcinogenesis. Cancer Res 1981;41:3761-3.

5 Owen RW, Dodo M, Thompson MH, et al. The faecal ratio of lithocholic to deoxycholic acid may be important aetiological factor in colorectal cancer. Biochem Soc Trans 1984 12:861-2.

6 Dean PD, Whitehouse MW. Inhibition of hepatic sterol oxidation by cholanic (bile) acids and their conjugates. Biochim Biophys Acta 1967;137:328-34.

7 Scholmerich J, Becher MS, Schmidt K, et al. Influence of hydroxylation and conjugation of bile acids on their membrane-damaging properties - studies on isolated hepamembrane-damaging properties - studies on isolated hepa-

8 tocytes and membrane vesicles. Hepatology 1984;4:661-6. Attwood SEA, Ball CS, Barlow AP, et al. Role of intragastric
and intraesophageal alkalinisation in the genesis of complications in Barrett's columnar lined oesophagus. Gut 1993 34:11-15.

9 Mattioli S, Piloti V, Felice V, et al. Ambulatory 24-hr pH monitoring of esophagus, fundus and antrum: a new technique for simultaneous study of gastroesophageal and duodenogastric reflux. Dig Dis Sci 1990;35:929-38.

10 Bechi P. Fiberoptic measurement of "alkaline" gastroesophageal reflux: technical aspects and clinical indications. Dis Eso 1994;7:131-8.
11 Caldwell MTP, Byrne PJ, Brazil N, et al. An ambulatory bile reflux monitoring system: an in vitro appraisal. Physiol Meas 1994;15:57-65.

12 Vaezi MF, LaCamera RG, Richter JE. Bilitec 2000 ambulatory duodenogastric reflux monitoring system. Studies on its validation and limitations. Am f Physiol 1994;30:10506.

13 Dowling RH, Small DM. The effect of $\mathrm{pH}$ on the solubility of varying mixtures of free and conjugated bile acids in solution. Gastroenterology 1968;54:1291.

14 Barthlen W, Libermann-Meffert D, Feussner H, et al. Effect of $\mathrm{pH}$ on human, pig and artificial bile acid preparation. Dis Eso 1994;7:27-30.

15 Kivilaakso E, Fromm D, Silen W. Effect of bile salts and related compounds on isolated oesophageal mucosa. Surgery 1980;87:280-5.

16 Lillemoe KD, Johnson LF, Harmon JW. Role of the components of the gastroduodenal contents in experimental acid esophagitis. Surgery 1982;92:276-84.

17 Nehra D, Watt P, Pye JK, et al. Automated esophageal reflux sampler - a new device used to monitor bile acid reflux in patients with gastro-esophageal reflux disease. 7 Med Eng Technol 1997;21:1-9.

18 Nehra D, Howell P, Pye JK, et al. Assessment of combined bile acid and $\mathrm{pH}$ profiles in using a new automated oesophageal reflux sampler in gastro-oesophageal reflux disease. Br f Surg 1998;85:134-7.

19 Hopwood D, Bateson MC, Milne G, et al. Effects of bile acids and hydrogen ion on the fine structure of oesphageal epithelium. Gut 1981;22:306-11.

20 Kappas A, Palmer RH. Selected aspects of steroid pharmacology. Pharmacol Rev 1963;15:123-67.

21 Pope JL, Parkinson TM, Olson JA. Action of bile salts on the metabolism and transport of water-soluble nutients by perfused rat jejunum in vitro. Biochim Biophys Acta 1966;130: 218-32.

22 Clark ML, Lanz HC, Senior JR. Bile salt regulation of fatty acid absorption and esterification in rat everted jejunal sacs in vitro and into thoracic duct lymph in vivo. $\mathcal{F}$ Clin Invest 1969;48:1587-99.

23 Holt PR. Competitive inhibition of intestinal bile salt absorption in the rat. Am f Physiol 1966;210:635-9.

24 Rosser BG, Gores GJ. Liver cell necrosis: cellular mechanisms and clinical implications. Gastroenterology 1995;108: $252-75$.

25 Johnsson F, Joelsson B, Floren CH, et al. Bile salts in the esophagus of patients with esophagitis. Scand $\mathcal{F}$ Gastroenterol 1988;23:712-16.

26 Iftikhar SY, Ledingham S, Steele RJC, et al. Bile reflux in columnar-lined Barrett's oesophagus. Ann R Coll Surg Engl 1993;75:411-16.

27 Stoker DL, Williams JG, Dewar EP, et al. The $\mathrm{pH}$ and concentration of bile in the oesophagus [abstract]. Gut 1988;29:A728-9.

28 Gotley DC, Morgan AP, Cooper MJ. Bile concentrations in the refluxate of patients with reflux oesophagitis. Br F Surg 1988:75:587-90.

29 Stein HJ, Feussner H, Kauer W, et al. Alkaline gastroesophageal reflux: assessment by ambulatory esophageal aspiration and $\mathrm{pH}$ monitoring. Am $\mathcal{F}$ Surg 1994;167:163-8.

30 Safaie-Shirazi S. Effect of pepsin on the ionic permeability of canine esophageal mucosa. F Surg Res 1977;22:5-8.

31 Salo J, Kivilaakso E. Contribution of trypsin and cholate to the pathogenesis of experimental alkaline reflux esophagitis. Scand $\mathcal{F}$ Gatroenterol 1984;19:875-81.

32 Lillemoe KD, Johnson LF, Harmon JW. Alkaline oesophagitis: a comparison of the ability of components of gastroduodenal contents to injure the rabbit oesophagus. gastroduodenal contents to inju
Gastroenterology 1983;85:621-8.

33 Armstrong D, Rytina ER, Murphy GM, et al. Gastric mucosal toxicity of duodenal juice constituents in the rat. Acute studies using ex vivo rat gastric chamber model. Dig Dis Sci 1994;39:327-39.

34 McKenzie D, Grayson T, Polk HC Jr. The impact of omeprazole and laparoscopy upon hiatal hernia and reflux esophagitis. 7 Am Coll Surg 1996;183:413-18.

35 Batzri S, Harmon JW, Schweitzer EJ, et al. Bile acid accumulation in gastric mucosal cells. Proc Soc Exp Biol Med 1991;197:393-9.

36 Goldstein JL, Schlesinger PK, Mozwecz HL, et al. Esophageal mucosal resistance- a factor in esophagitis. Gastroenterol Clin North Am 1990;19:565-86.

37 Domellof L, Reddy B, Weisburger JH. Microflora and deconjugation of bile acids in alkaline reflux after partial gastrectomy. Am f Surg 1980;140:291-4.

38 Poxon VA, Morris DI, Youngs DJ, et al. Exposure to bile acids and bacteria over 24 hours following partial gastrectomy, vagotomy and pyloroplasty. World F Surg 1986;10 tomy, 98 .

39 Matikainen M, Laatikainen T, Kalima T, et al. Bile acid composition and oesophagitis after total gastrectomy. Am $\mathcal{F}$ Surg 1982;143:196-8

40 Karmelli Y, Stalnikowitz R, Eliakim R, et al. Conventional dose of omeprazole alters gastric flora. Dig Dis Sci 1995;40: 2070-3.

41 Thorens J, Froehlich F, Schwizer W, et al. Bacterial overgrowth during treatment with omeprazole compared with cimetidine: a prospective randomised double blind study. Gut 1996;39:54-9. 